\title{
Variabilidade climática e controles do clima em unidades de conservação: estudo de caso no Parque Estadual de Itapuã, Viamão/RS, sob Domínios Atmosféricos Tropicais
}

\author{
Climate variation and climate controls in conservation units: a study case of Itapuã \\ State Park, Viamão/RS, under Tropical Atmospheric Domain
}

\author{
Cássio Arthur Wollmann*1 \\ ${ }^{1}$ Doutor, Departamento de Geociências, Universidade Federal de Santa Maria, Santa Maria, Brasil
}

\begin{abstract}
Resumo
O objetivo geral desta pesquisa consistiu em analisar a distribuição espacial dos atributos do clima no Parque Estadual de Itapuã, localizado no município de Viamão/RS, sob domínio anticiclonal tropical atlântico e tropical continental, em dois horários de coleta. Para a realização desta pesquisa climática in loco necessitou-se a realização de trabalho de campo na Unidade de Conservação, no qual realizou-se transecto móvel nas áreas de maior expressão topográfica e praias, em quinze pontos distintos. Mediu-se temperatura do bulbo seco, temperatura do bulbo úmido e umidade relativa do ar. Foram confeccionados mapas de variação espacial dos atributos do clima levantados e utilizou-se de cartas sinóticas e imagens de satélite para identificação dos sistemas atmosféricos atuantes. Após análise climática e cartográfica, viu-se que a variabilidade espacial dos atributos é tão diversa e dinâmica quanto à natureza paisagística do parque e seus controles climáticos, pois a temperatura do bulbo seco teve sua variabilidade entre os dois horários associada exclusivamente à orientação das vertentes, enquanto que a temperatura do bulbo seco à altitude nos diversos pontos de coleta. Já a variação da umidade relativa do ar esteve ligada, na parte da manhã, à orientação das vertentes, e na parte da tarde, à presença de vegetação de maior porte.
\end{abstract}

Palavras-chave: Variabilidade climática, Unidades de Conservação, Parque Estadual de Itapuã, Circulação Atmosférica Regional, Domínio Tropical.

\begin{abstract}
This research concerns in to analyze the spatial distribution of climate in Itapua State Park, located in the municipality of Viamão/RS under domain anticiclonal tropical Atlantic and tropical continental in two hours of collection. For this research climate in loco needed to carry out fieldwork in park, which was held mobile transect in areas of high topographic expression and beaches, in fifteen different points. It was measured dry bulb temperature, wet bulb temperature and relative humidity. It was made maps of the spatial variation of climate raised and used for synoptic maps and satellite images for identification of active weather systems. After climatic analysis and mapping, it was seen that the spatial variability of attributes is as diverse and dynamic as the nature of the landscape park and its climatic controls, because the dry bulb temperature was variability between the two schedules associated exclusively to the orientation of the strands while the dry bulb temperature at altitude in the various collection points. The variation of the relative humidity was linked, in the morning, the orientation of the strands, and in the afternoon, the presence of vegetation larger.
\end{abstract}

Keywords: Climate variability, Conservation Units, Itapuã State Park, Regional Atmospheric Circulation, Tropical Atmosphere Domain.

* cassio_geo@yahoo.com.br

Recebido: 17/03/2014 Aceito: 17/03/2014 


\section{Introdução}

$\mathrm{N}$ o Brasil, os estudos climáticos relacionados às unidades de conservação ainda constituem-se uma minoria dentro da seara geográfica, mesmo com a criação do Sistema Nacional de Unidades de Conservação (SNUC), regulamentado pela Lei Federal No 9.985, de 18 de julho de 2000, que em seu Artigo $50^{\circ}$, dispõe que o clima também é considerado uma das características marcantes de uma região, e por tal razão, merece cadastro e proteção dos órgãos ambientais nas esferas federal, estaduais e municipais competentes.

A localização do Parque Estadual de Itapuã na Região Metropolitana de Porto Alegre, no município de Viamão, entre o Lago Guaíba e a Laguna dos Patos, seus valores ecológicos, culturais e paisagísticos fazem desta unidade uma das áreas mais procuradas pelos habitantes da região como forma de lazer, especialmente no verão, e uma das unidades de conservação de maior destaque do Sistema Estadual de Unidades de Conservação.

Para o Parque Estadual de Itapuã (PEI), o clima e sua dinâmica regional passa a ser um atributo marcante para a vida nesta unidade de conservação. Nesse sentido, entender a relação existente entre a dinâmica do meio atmosférico e do meio biótico e terrestre é, portanto, um dos objetivos da Climatologia Geográfica.

Ainda, no âmago das Unidades de Conservação, o monitoramento climático das mesmas ainda constituise em ramo científico pouco estudado no Brasil, o que pode auxiliar significativamente no Plano de Manejo das UCs, não só na sua construção, bem como na sua plena execução de monitoramento.

No que concernem os estudos sobre clima e Unidades de Conservação (UC) no Brasil, tais pesquisas restringemse às de LIMA (2009) e especialmente SERAFINI (2010), que investigaram, respectivamente, o clima em áreas de manguezais da Serra do Mar e a relação climática referente ao desmatamento das veredas em uma UC localizada em Minas Gerais. Além disso, o trabalho de KOURY, et. al. (2011) recentemente salienta a urgente necessidade de inclusão dos estudos de climatologia na gestão das Unidades de Conservação.

Para o Rio Grande do Sul e suas UCs, há o trabalho de WOLLMANN; SIMIONI (2013), que envolve o estudo do clima nessas áreas protegidas, e sua relação com a dinâmica natural e a ocupação antrópica, seja no seu interior, seja no seu entorno, o que caracterizam impactos às mesmas.

Assim sendo, o objetivo geral desta pesquisa consistiu em analisar a distribuição espacial dos atributos do clima (umidade relativa do ar, temperatura do bulbo seco e úmido), nas áreas topograficamente elevadas e praias do Parque Estadual de Itapuã, em Viamão/RS, verificando a influência dos controles geográficos do clima sob condições atmosféricas de domínio tropical atlântico e continental.

\section{Localização e caracterização geográfica da área de estudo}

O Parque Estadual de Itapuã (PEI), localizado no Distrito de mesmo nome, no município de Viamão, distante $57 \mathrm{~km}$ do centro de Porto Alegre, na desembocadura do Lago Guaíba com a Laguna dos Patos, entre as coordenadas $50^{\circ} 50^{\prime}$ e $51^{\circ} 05^{\prime} \mathrm{W}$ e $30^{\circ} 20^{\prime}$ e $30^{\circ} 27^{\prime} \mathrm{S}$, é uma Unidade de Conservação de Proteção Integral e abriga uma das últimas amostras dos ambientes originais da Região Metropolitana da capital (Figura 01).

A Região Metropolitana de Porto Alegre abrange aproximadamente 3\% da área do Estado e apresenta a maior concentração populacional, com cerca de $34 \%$ do total da população do Rio Grande do Sul. Nesta, as principais atividades econômicas estão constituídas por serviços, varejo e transformação.

O município de Viamão integrante da Região Metropolitana, onde se localiza o Parque, possui uma área de $1.612 \mathrm{~km}^{2}$ e população de aproximadamente 240.000 habitantes (IBGE, 2010). Para a proteção ambiental dessa área em função da crescente expansão urbana e das atividades agrícolas em seu entorno, o PEI foi criado através de decreto estadual, e está constituído pelas terras desapropriadas pelo Decreto no 22.535, de 14 de julho de 1973, pelo Decreto no 25.162 , de 23 de dezembro de 1976, e pelo Decreto oㅜ 33.886, de 11 de março de 1991, e pelo Decreto ${ }^{\circ}$ 35.016, de 21 de dezembro de 1993.

A área original do Parque, em 1973, abrangia 1.535 ha e foi ampliada em 1976 para 3.783 ha. Em 1991, a lagoa Negra passou a fazer parte da área do Parque, que abrangia então 5.533 ha. Com a anexação das ilhas das Pombas, do Junco e da Ponta Escura, em 1993, a área foi ampliada em 33,50 ha, totalizando atualmente 5.566,50 ha (PLANO DE MANEJO, 1996).

Segundo a Fundação Zoobotânica do Estado do Rio Grande do Sul (FZBRS, 2012), o PEI localiza-se dentro do Bioma Pampa, na transição entre o continente e o litoral lagunar, em duas ecorregiões com vegetação distintas: os Campos Sulinos e a Vegetação de Restingas da Costa Atlântica.

$\mathrm{Na}$ área do Parque coexistem as formas do Escudo Sul-rio-grandense e da Planície Costeira. A primeira província é representada pelas coxilhas e morros com altitudes geralmente entre 50 e 200 metros, enquanto a segunda apresenta como relevos mais característicos extensas superfícies praticamente horizontais e planas, ou levemente onduladas à qual, no extremo leste estão associadas grandes pântanos em fase de colmatação que avançam até o limite das praias arenosas lacustres - Praia das Pombas e Praia da Pedreira. (PLANO DE MANEJO, 1996).

As altitudes no Parque variam de 5 a 263m estando às formas de relevo associadas às duas principais províncias geomorfológicas do Estado: os granitos do Escudo Sul-rio-grandense e os sedimentos da Planície Costeira. As terras altas, com mais de $100 \mathrm{~m}$ acima do nível do 


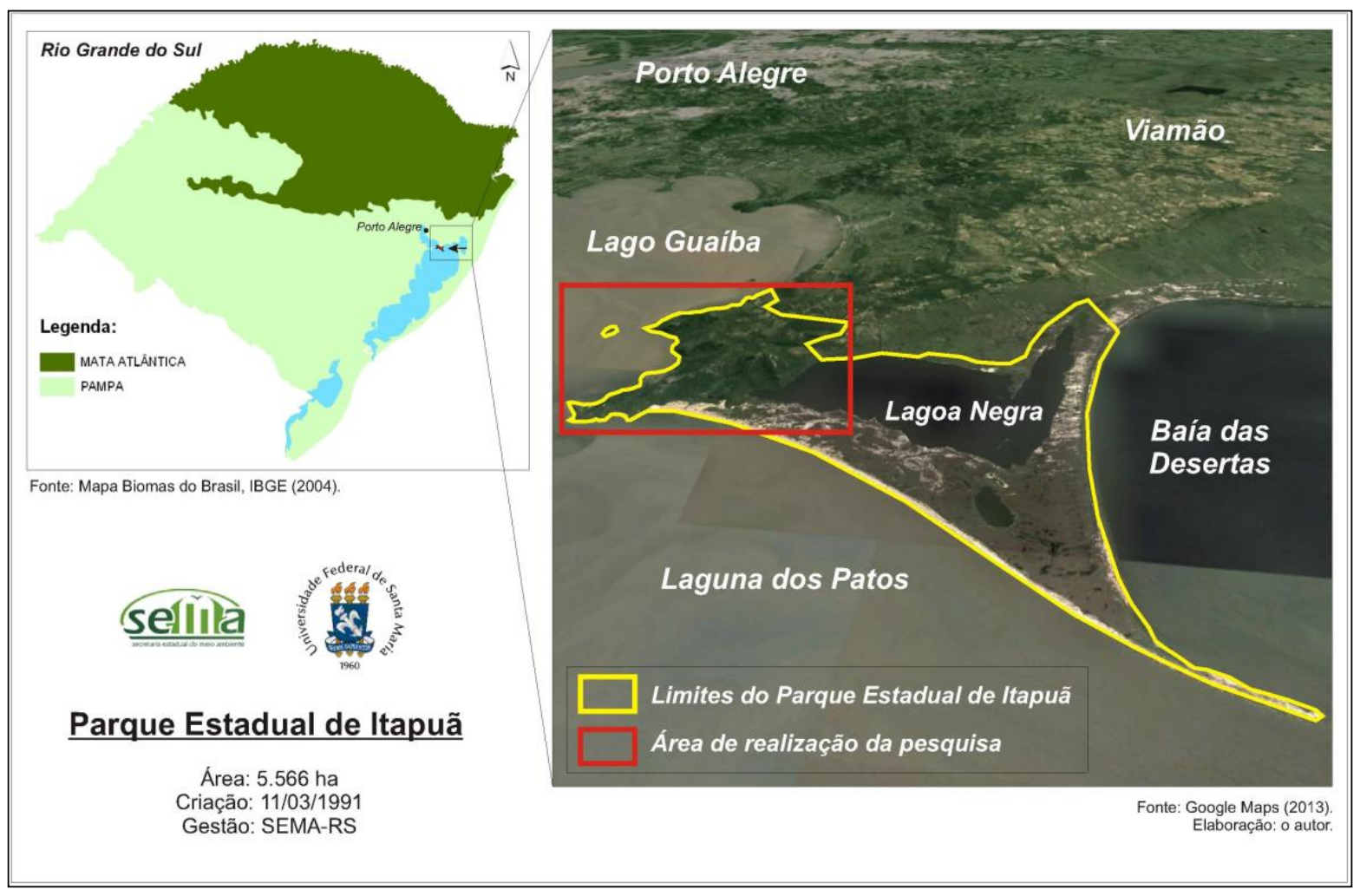

Figura 01 - Localização do Parque Estadual de Itapuã (PEI).

Org. e adapt.: Wollmann (2013).

mar, localizam-se na faixa oeste e estão representadas pelos morros, como o da Grota com $263 \mathrm{~m}$, o pontal de Itapuã com 170m, o morro do Campista com 192 m, o morro do Araçá com 193 m, o morro da Fortaleza com $172 \mathrm{~m}$ e o morro das Pombas com $161 \mathrm{~m}$.

Para melhor visualizar a caracterização topográfica da área de estudo, a Figura 02 apresenta um a cobertura do solo, hipsometria e orientação de vertentes da área estudada, além de um trecho do transecto percorrido, que será melhor descrito no item materiais e métodos.

O clima local classifica-se como subtropical úmido, sem estação seca, com temperaturas médias anuais oscilando em torno de $17,5^{\circ} \mathrm{C}$ e precipitação média anual entre 1.100 a $1.300 \mathrm{~mm}$. As chuvas são bem distribuídas ao longo do ano e os verões quentes, com temperatura média do mês mais quente superior aos $22^{\circ} \mathrm{C}$.

$\mathrm{O}$ vento predominante é o nordeste, com velocidade média aproximadamente de $4,4 \mathrm{~m} / \mathrm{s}$, sendo que no inverno predominam os ventos do sul ou sudoeste, particularmente fortes, responsáveis pela correnteza lacustre costeira e diretamente, pela existência e evolução atual dos pontais arenosos costeiros que se desenvolvem para o leste, projetando-se para dentro da Laguna dos Patos (Germ, 1975).

Ainda, nevoeiros são frequentes e a umidade atmosférica elevada devido à presença durante todo o ano das massas de ar marítimas e a proximidade das grandes massas lacustres, o que concorre também para moderar os rigores do verão (brisa lacustre) e dificultar a ocorrência de geadas hibernais.

Do ponto de vista hidrográfico, o Parque Estadual de Itapuã apresenta-se estrategicamente situado entre dois corpos d'água de grande importância para o Estado: lago Guaíba e a laguna dos Patos, além de vários banhados formando habitats de grande importância para a conservação de espécies típicas da fauna e flora local (Volkmer-Ribeiro, 1981).

\section{Materiais e métodos}

Para a realização desta pesquisa climática in loco necessitou-se a realização de trabalho de campo no Parque Estadual de Itapuã (PEI), que ocorreu no dia 01 de fevereiro de 2013, no qual foi realizado transecto móvel selecionando-se apenas em uma parte do parque, que correspondera às áreas topograficamente mais elevadas e as estradas de acesso às Praias das Pombas e da Pedreira (ambas de uso aberto a turistas).

Percorreu-se cerca de 6.600 metros, e a coleta foi feita em 15 (quinze) pontos distintos (Figura 03), em dois horários: às $9 \mathrm{~h}$ da manhã e $15 \mathrm{~h}$ da tarde, tomando-se cuidado em função da ocorrência do horário do verão. O tempo de realização dos transectos nos dois horários proposto foi de aproximadamente 20 minutos.

Foram feitas as coletas de temperatura do bulbo seco, 


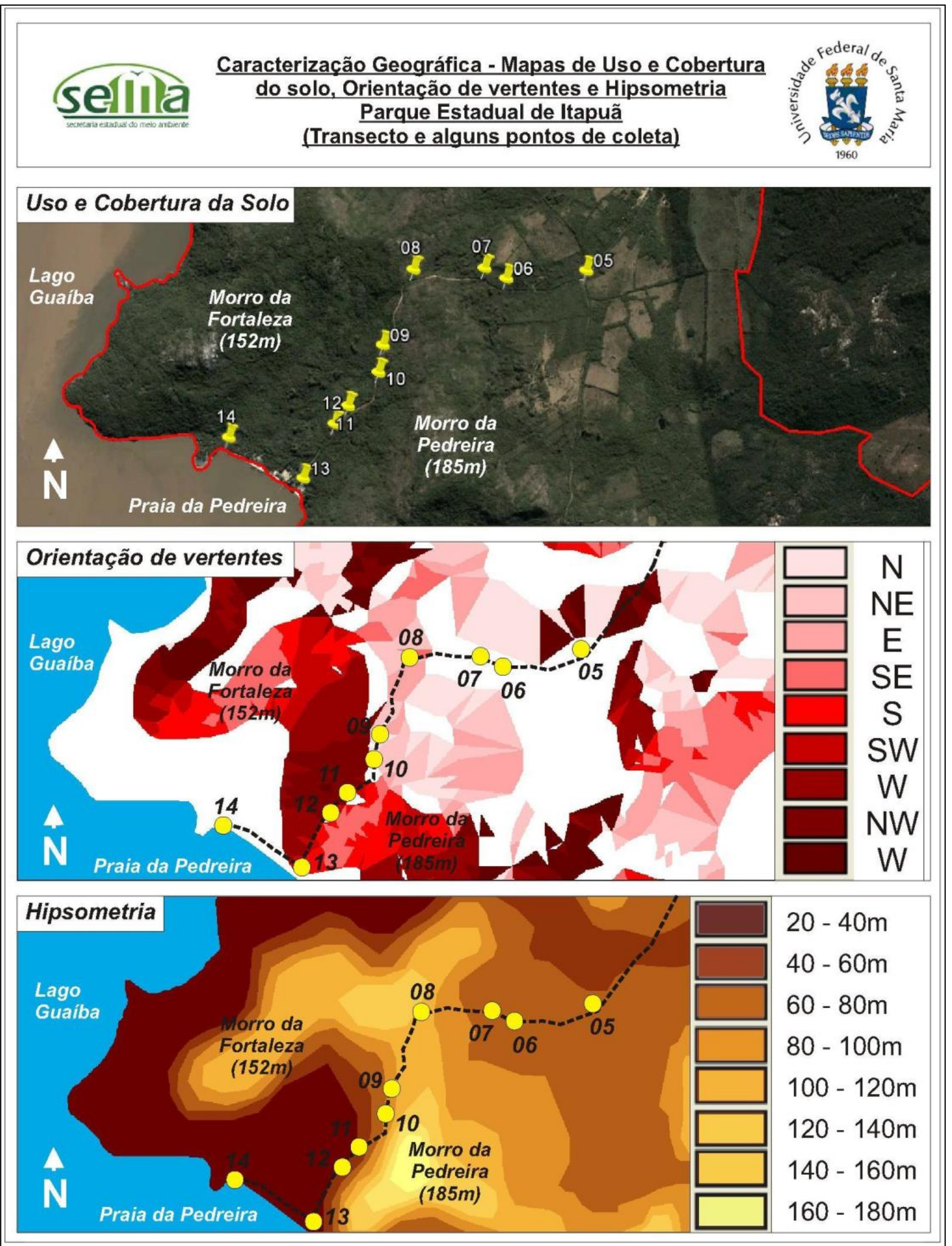

Figura 02 - Cobertura do solo, hipsometria e orientação de vertentes da área estudada no Parque Estadual de Itapuã - Viamão/RS.

Org. e adapt.: Wollmann (2013). 


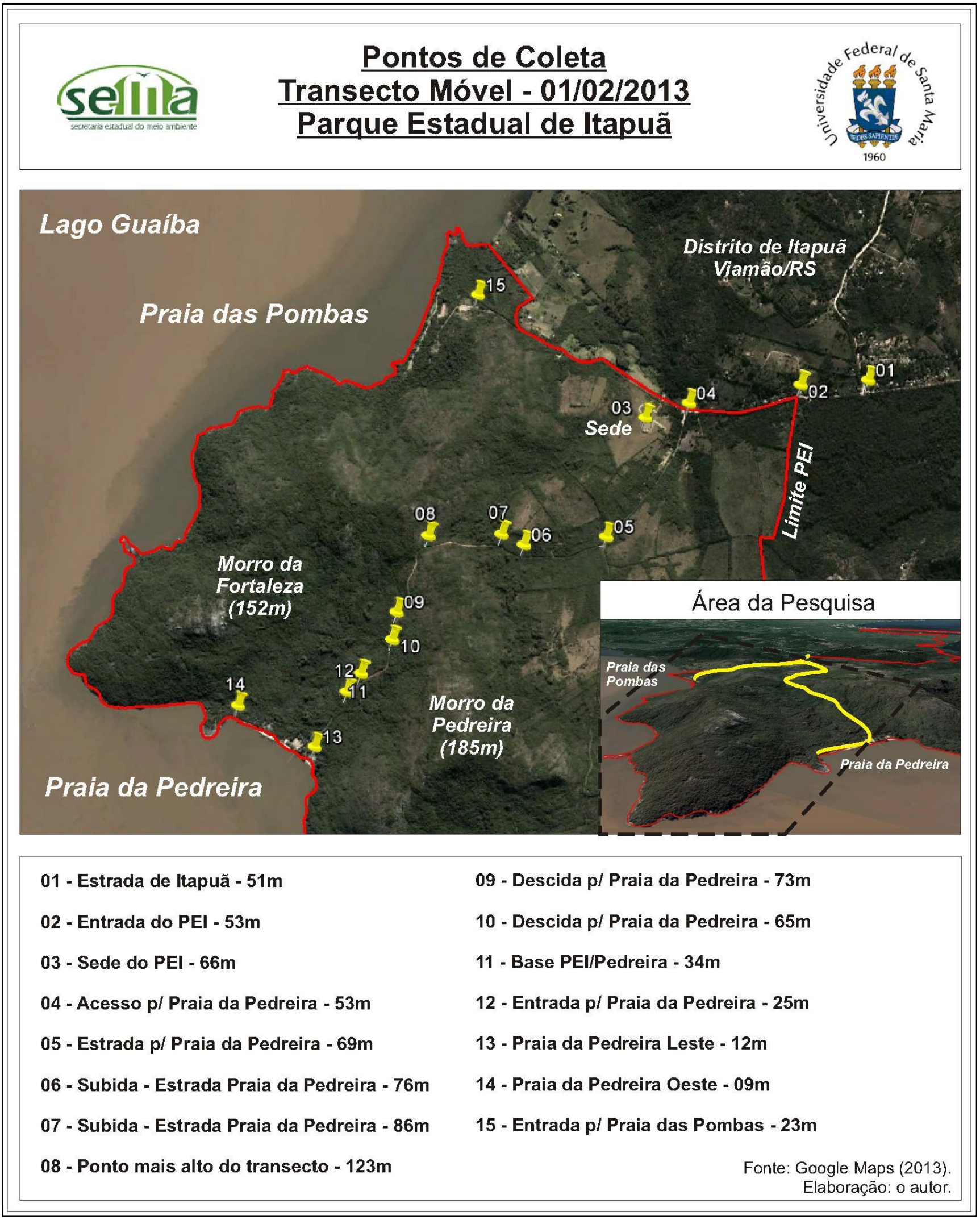

Figura 03 - Localização dos pontos de coleta dos atributos climáticos no Parque Estadual de Itapuã (PEI) por meio de transecto móvel. Data da coleta: 01/02/2013.

Org. e adapt.: Wollmann (2013). 
temperatura do bulbo úmido e umidade relativa do ar no PEI nos 15 pontos diferentes, através de transecto móvel, e utilizaram-se os Dataloggers de Temperatura de Umidade, da marca Instrutherm HT-500 (Figura 04). A realização do transecto móvel foi feita com a utilização de um carro, e tomou-se devido cuidado para que a velocidade média do veículo durante a realização do trajeto não ultrapassasse os $20 \mathrm{~km} / \mathrm{h}$ para que o vento não influenciasse nas medições meteorológicas.

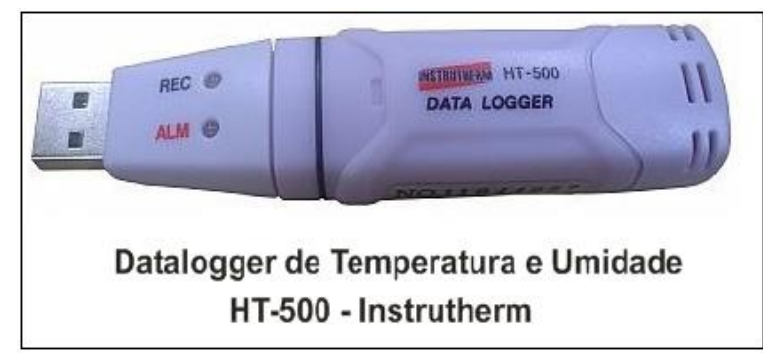

Figura 04 - Equipamento de coleta dos dados no PEI. Adaptação: Wollmann (2013).

Os critérios de seleção dos 15 pontos de coleta deu-se em função da altitude e da mudança paisagística entre os pontos, que ora apresentavam-se sob influência de vegetação arbóreo-arbustivas, e ora como vegetação rasteira, típica no PEI, além das coletas nas praias, o que em teoria permitiria verificar a influência do Lago Guaíba e da altitude nas medições.

Os Pontos 01, 02, 03 e 04 (entrada do PEI) apresentavam-se caractarísticas paisagísticas homogêneas, sendo o Ponto 03, o mais alto entre estes. Os Pontos 05 a 12 localizavam-se na estrada que dá aceso à Praia da Pedreira, e a paisagem apresentava-se bastante heterogênea, passando-se desde paisagens com vegetação arbóreo-arbustivas ou rasteiras, bem como por áreas de regeneração pós criação da unidade de conservação. Por fim, os pontos 13, 14 e 15 referem-se às duas praias existentes na área selecionada para o estudo, ambas localizadas às margens do Lago Guaíba, e muito utilizadas por turistas e moradores do entorno do PEI para atividades de lazer vernais.

Para melhor caracterizar os pontos de realização de coleta dos dados, a Figura 05 apresenta uma fotografia dos mesmos qual foi feito o monitoramente instantâneo dos atributos do clima.

De posse dos dados coletados em campo, foram construídas tabelas, com auxílio do software Microsoft Excel 2003. Tais tabelas referem-se ao banco de dados do SIG Surfer 8.0, que gerou as isolinhas de variabilidade dos elementos do clima no PEI. Para a construção do banco de dados do SIG citado deve-se ordenar em cada coluna da tabela as coordenadas UTM X e Y do ponto coletado (que foi marcado com auxílio de GPS utilizado juntamente com o Datalogger), bem como o registro do atributo climático.

A segunda etapa de tratamento em ambiente de SIG consiste na geração das isolinhas dos elementos climáticos, que puderam ser construídas utilizando-se o SIG Surfer 8.0. Para tal, em ambiente de trabalho, foi necessário importar as tabelas (banco de dados) construídas na primeira etapa no ambiente Excel 2003. Deve-se localizar o arquivo Excel (formato .xls) o qual possui o banco de dados, e ao importá-lo para o programa e utilizou-se a "krigagem" como método de interpolação geoestatística.

A última etapa do mapeamento das variáveis climáticas coletadas consistiu na exportação dos vetores mapeados (isolinhas) do Surfer 8.0 para o software ArcGis 3.2 Free Edition, no qual transformou-se as isolinhas em formato Shapefile, pois se torna necessária a edição dos vetores para criação do banco de dados e edição final do mapa, com os limites da área de coleta dentro da Unidade de Conservação, bem como das estradas e do Lago Guaíba.

Assim, foram construídos, ao final, 06 (seis) mapas dos atributos climáticos e sua variabilidade espacial na Estação Ecológica do Taim: Temperatura do ar (Bulbo seco e úmido) e umidade relativa do ar para os dois horários de coleta na data de 01 de fevereiro de 2013: às $9 \mathrm{~h}$ da manhã e às $15 \mathrm{~h}$ da tarde, horários oficiais do Instituto Nacional de Meteorologia (INMET).

Ainda, foram coletados os dados climáticos do dia 01 de fevereiro de 2013 da Estação Meteorológica de Porto Alegre/RS, que pertence è Rede INMET, os quais foram comparados com os dados coletados em campo. Também, coletaram-se cartas sinóticas da Marinha do Brasil e imagens de Satélite do CPTEC-INPE para averiguação dos sistemas atmosféricos reinantes no dia do campo.

\section{Análise e discussão dos resultados}

\subsection{Variabilidade dos atributos do clima no transecto e identificação dos sistemas atmos- féricos regionais dominantes no Parque Es- tadual de Itapuã e Região Metropolitana de Porto Alegre/RS.}

Após coleta dos dados em campo com auxílio dos Dataloggers, construiu-se a Tabela 01 , com a qual se pode melhor visualizar a medição e a variação dos atributos do clima (temperatura de bulbo seco e úmido, e umidade relativa do ar), às $09 \mathrm{~h}$ da manhã (sem influência do horário de verão, que corresponderia às $10 \mathrm{~h}$ ), do dia 01 de fevereiro de 2013, nos quinze pontos de coleta.

A Tabela 02 apresenta os valores relativos à medição da temperatura de bulbo seco e úmido, e umidade relativa do ar, às $15 \mathrm{~h}$ da tarde (sem influência do horário de verão, que corresponderia às $15 \mathrm{~h}$ ), do dia 01 de fevereiro de 2013, nos quinze pontos de coleta, no mesmo transecto realizado às $10 \mathrm{~h}$ da manhã. 


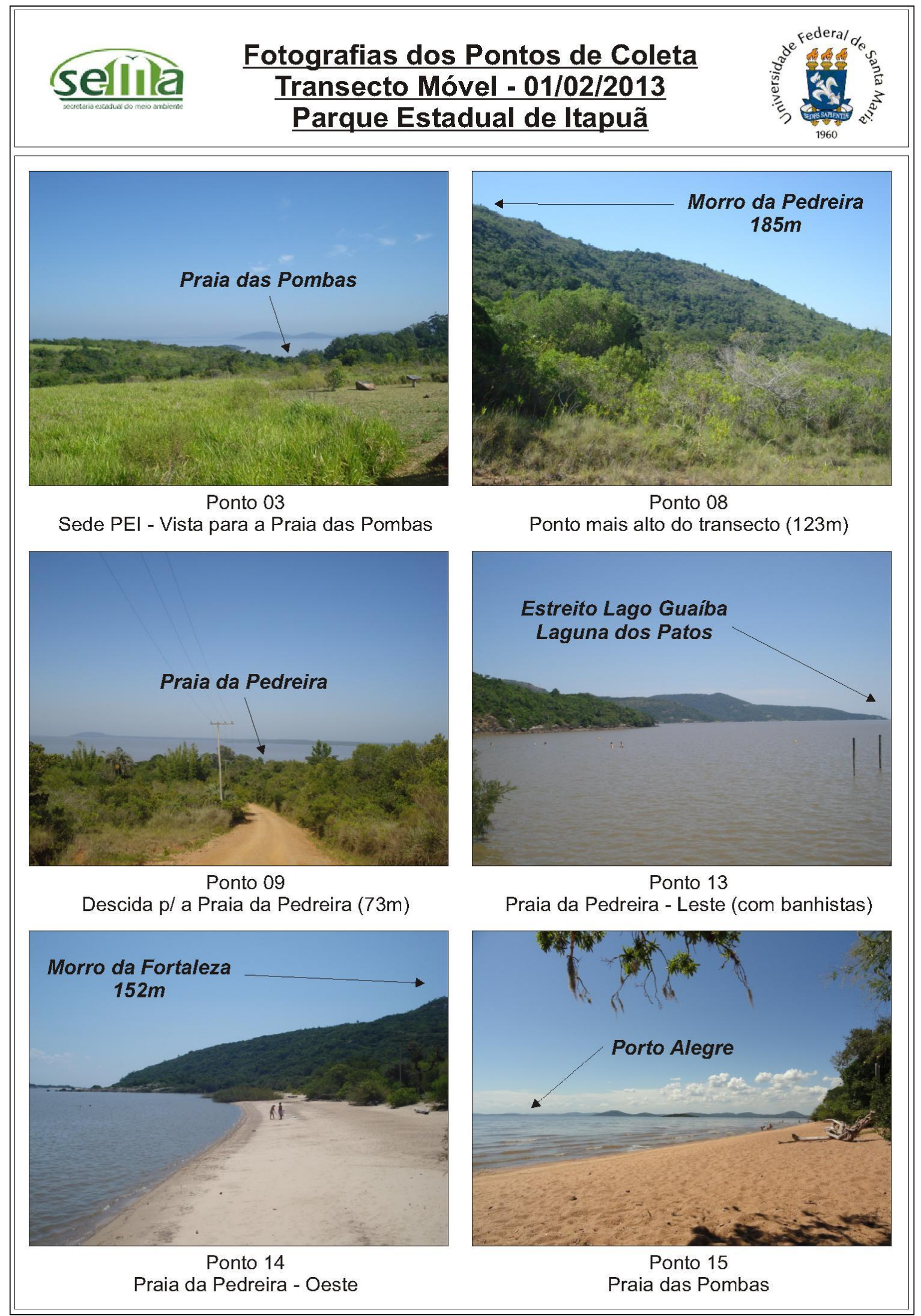

Figura 05 - Fotos de seis pontos de coleta dos dados e suas paisagens características no Parque estadual de Itapuã, Viamão/RS.

Fotos: Wollmann (2013). 
Tabela 01 - Atributos climáticos coletados no Parque estadual de Itapuã, nos quinze pontos de coleta do transecto, às 09h da manhã (corrigindo-se o horário de verão).

\begin{tabular}{|c|c|c|c|c|c|}
\hline Ponto & Horário & Altitude $($ anm $)$ & TBS $\left({ }^{\circ} \mathrm{C}\right)$ & TBU $\left({ }^{\circ} \mathrm{C}\right)$ & URA (\%) \\
\hline 01 & $09 h 54 \mathrm{~min}$ & $52 \mathrm{~m}$ & 31,0 & 25,5 & 62 \\
\hline 02 & $09 \mathrm{~h} 56 \mathrm{~min}$ & $53 \mathrm{~m}$ & 30,0 & 25,5 & 69 \\
\hline 03 & $10 \mathrm{~h} 13 \mathrm{~min}$ & $65 \mathrm{~m}$ & 32,0 & 26,0 & 61 \\
\hline 04 & $10 \mathrm{~h} 16 \mathrm{~min}$ & $56 \mathrm{~m}$ & 31,0 & 25,5 & 63 \\
\hline 05 & $10 \mathrm{~h} 18 \mathrm{~min}$ & $68 \mathrm{~m}$ & 30,0 & 25,0 & 64 \\
\hline 06 & $10 \mathrm{~h} 19 \mathrm{~min}$ & $78 \mathrm{~m}$ & 30,0 & 25,0 & 64 \\
\hline 07 & $10 \mathrm{~h} 20 \mathrm{~min}$ & $88 \mathrm{~m}$ & 31,0 & 26,0 & 64 \\
\hline 08 & $10 \mathrm{~h} 22 \mathrm{~min}$ & $120 \mathrm{~m}$ & 32,5 & 27,0 & 64 \\
\hline 09 & $10 \mathrm{~h} 24 \mathrm{~min}$ & $74 \mathrm{~m}$ & 31,0 & 26,5 & 69 \\
\hline 10 & $10 \mathrm{~h} 26 \mathrm{~min}$ & $62 \mathrm{~m}$ & 30,5 & 26,0 & 68 \\
\hline 11 & $10 \mathrm{~h} 27 \mathrm{~min}$ & $27 \mathrm{~m}$ & 31,0 & 27,0 & 73 \\
\hline 12 & $10 \mathrm{~h} 28 \mathrm{~min}$ & $19 \mathrm{~m}$ & 30,0 & 25,5 & 69 \\
\hline 13 & $10 \mathrm{~h} 35 \mathrm{~min}$ & $07 \mathrm{~m}$ & 31,0 & 27,0 & 71 \\
\hline 14 & $10 \mathrm{~h} 40 \mathrm{~min}$ & $08 \mathrm{~m}$ & 32,0 & 27,0 & 66 \\
\hline 15 & $10 \mathrm{~h} 15 \mathrm{~min}$ & $23 \mathrm{~m}$ & 31,5 & 27,0 & 65 \\
\hline Média & - & - & 31,0 & 26,1 & 66 \\
\hline
\end{tabular}

Fonte: Trabalho de Campo (Fev.-2013).

Org.: Wollmann (2013).

De acordo com os dados da Tabela 01, que podem ser cruzados com a altitude dos pontos de coleta, o Ponto 08, que corresponde a maior altitude, registrou a maior temperatura às $9 \mathrm{~h}$ da manhã, seguido por pontos de menor altitude, especialmente os Pontos 03 e 14, que correspondem respectivamente à Sede do PEI e à Praia da Pedreira. Esses lugares possuem em comum o fato de serem os mais abertos do ponto de vista da vegetação, pois não apresentam árvores, muito menos dossel; assim, a radiação solar sem interferência deste controle (vegetação) pode afetar de forma mais significativa a temperatura de bulbo seco (TBS) neste horário da manhã.

A temperatura do bulbo úmido (TBU) justamente nos Pontos 08 (idem à TBS) e nos pontos 13, 14 e 15, que correspondem aos mais próximos do Lago Guaíba. Assim, vê-se a relação direta entre a TBU e a presença de grandes corpos d'água na parte da manhã no Parque Estadual de Itapuã.

A umidade relativa do ar (URA) apresentou os maiores valores nos Pontos 09, 10, 12 e 13, que correspondem aos pontos que se localizavam nas vertentes com orientação sul do PEI, que neste horário da manhã, ainda não recebiam radiação solar de forma mais direta, o que pode influenciar na umidade presente no ar, dado ao atraso do processo de evaporação por influência topoclimática no PEI.

Quando comparados com os dados da Tabela 02, observou-se que os mesmos pontos de coleta às $15 \mathrm{~h}$ do mesmo dia relativos à TBS registraram valores inferiores quando comparados com os Pontos 09 a 15, que correspondem às vertentes com orientação oeste, sul e os locais próximos às praias, que possuem menor altitude no PEI.

Já a TBU não apresentou grande variação entre os 15 pontos coletados, à exceção do Ponto 12 , que apresentou valores de $32,0^{\circ} \mathrm{C}$. O mesmo pode ser observado na URA, cujos valores em média foram inferiores aos registrados pela manhã, devido ao aquecimento do ar durante o máximo de balanço positivo de energia, aumentando o processo de evaporação na atmosfera e diminuindo os valores de URA.

Quando comparados os valores médios, a TBS às $9 \mathrm{~h}$ e $15 \mathrm{~h}$ foi de, respectivamente $31,0^{\circ} \mathrm{C}$ e $35^{\circ} \mathrm{C}$, enquanto que na Estação Meteorológica do INMET de Porto Alegre, tal registrou foi de $28,0^{\circ} \mathrm{C}$ e $36,0^{\circ} \mathrm{C}$ nos dois horários respectivamente. Considerando que a Estação Oficial de Porto Alegre dista aproximadamente 40 quilômetros ao norte do Parque Estadual de Itapuã, e está a $41 \mathrm{~m}$ de altitude, a TBS às $9 \mathrm{~h}$ registrou $1^{\circ} \mathrm{C}$ a menos em comparação com o PEI, enquanto à tarde, o registro foi de $1^{\circ} \mathrm{C}$ a mais.

Nesse sentido, observa-se que na data do transecto, a amplitude térmica no PEI é inferior à da estação da capital gaúcha, sendo, provavelmente, influência da vegetação nativa da unidade de conservação e presença dos corpos d'água de grande importância (Lago Guaíba 
Tabela 02 - Atributos climáticos coletados no Parque estadual de Itapuã, nos quinze pontos de coleta do transecto, às $15 \mathrm{~h}$ da tarde (corrigindo-se o horário de verão).

\begin{tabular}{|c|c|c|c|c|c|}
\hline Ponto & Horário & Altitude (anm) & TBS $\left({ }^{\circ} \mathrm{C}\right)$ & TBU $\left({ }^{\circ} \mathrm{C}\right)$ & URA (\%) \\
\hline 01 & $15 \mathrm{~h} 45 \mathrm{~min}$ & $52 \mathrm{~m}$ & 34,0 & 29,0 & 66 \\
\hline 02 & $15 \mathrm{~h} 50 \mathrm{~min}$ & $53 \mathrm{~m}$ & 34,0 & 28,5 & 63 \\
\hline 03 & $15 \mathrm{~h} 55 \mathrm{~min}$ & $65 \mathrm{~m}$ & 34,5 & 29,0 & 64 \\
\hline 04 & $15 \mathrm{~h} 56 \mathrm{~min}$ & $56 \mathrm{~m}$ & 33,5 & 28,5 & 66 \\
\hline 05 & $15 \mathrm{~h} 56 \mathrm{~min}$ & $68 \mathrm{~m}$ & 33,5 & 28,0 & 65 \\
\hline 06 & $15 \mathrm{~h} 57 \mathrm{~min}$ & $78 \mathrm{~m}$ & 33,5 & 28,5 & 67 \\
\hline 07 & $15 \mathrm{~h} 58 \mathrm{~min}$ & $88 \mathrm{~m}$ & 33,5 & 28,5 & 67 \\
\hline 08 & $16 \mathrm{~h} 00 \mathrm{~min}$ & $120 \mathrm{~m}$ & 34,5 & 29,0 & 63 \\
\hline 09 & $16 \mathrm{~h} 02 \mathrm{~min}$ & $74 \mathrm{~m}$ & 35,0 & 29,0 & 62 \\
\hline 10 & $16 \mathrm{~h} 03 \mathrm{~min}$ & $62 \mathrm{~m}$ & 36,0 & 29,5 & 59 \\
\hline 11 & $16 \mathrm{~h} 04 \mathrm{~min}$ & $27 \mathrm{~m}$ & 37,0 & 30,5 & 59 \\
\hline 12 & $16 \mathrm{~h} 05 \mathrm{~min}$ & $19 \mathrm{~m}$ & 37,5 & 32,0 & 63 \\
\hline 13 & $16 \mathrm{~h} 07 \mathrm{~min}$ & $07 \mathrm{~m}$ & 35,0 & 28,0 & 56 \\
\hline 14 & $16 \mathrm{~h} 08 \mathrm{~min}$ & $08 \mathrm{~m}$ & 37,0 & 28,5 & 56 \\
\hline 15 & $15 \mathrm{~h} 47 \mathrm{~min}$ & $23 \mathrm{~m}$ & 36,5 & 28,5 & 60 \\
\hline Média & - & - & 35,0 & 29,0 & 62 \\
\hline
\end{tabular}

Fonte: Trabalho de Campo (Fev.-2013).

Org.: Wollmann (2013).

e Laguna dos Patos), os grandes mantenedores da menos amplitude térmica quando comparada com uma estação localizada em área urbana, mas mesmo assim, dentro dos padrões da Organização Mundial Meteorológica (OMM).

A TBU média nos dois horários dos transectos foi de $26,1^{\circ} \mathrm{C}$ às $9 \mathrm{~h}$ e de $29,0^{\circ} \mathrm{C}$ às 15 . Esse aumente é considerado normal dado ao aquecimento e expansão do ar, o que confere à atmosfera maior capacidade de conter umidade, que pode ser representada pela TBU.

A URA, por sua vez, mostrou-se inversamente proporcional à TBS e TBU, sendo o valor médio às $9 \mathrm{~h}$ de $66 \% \mathrm{e}$ às $15 \mathrm{~h}$ de $62 \%$. Na estação meteorológica do INMET, em Porto Alegre, os registros de URA nos dois horários foram de, respectivamente, $68 \%$ e $52 \%$. Quando comparados os dados do PEI com os da estação do INMET, amplitude higrométrica no Parque Estadual de Itapuã foi menor, influência de controles climáticos, como vegetação e presença dos corpos hídricos de grande importância para a unidade de conservação, que, dado ao aquecimento dos mesmos, favorecem à evaporação e aumentam a URA ainda que esta diminua à tarde por influência do maior aquecimento do ar quando comparado com os valores de manhã e da Estação do INMET.

Cabe salientar que estes registros de temperatura e umidade, ainda que sofram influência dos principais controle climáticos do PEI, como altitude, vegetação e corpos hídricos, os mesmos possuem variabilidade recíproca à circulação atmosférica regional e sub-regional dominante no dia da medição (01/02/2013), que corresponde ao verão do Hemisfério Sul, logo, as temperaturas em média estão mais elevadas caso seja feita uma comparação com outra estação do ano.

Para relação entre os dados coletados em campo e a identificação dos sistemas atmosféricos dominantes, foram utilizadas as cartas sinóticas e imagens de satélite das $00 \mathrm{~h}$ e $12 \mathrm{~h}$, conforme horários oficiais da Marinha do Brasil para confecção das cartas isobáricas, que podem ser melhor visualizadas na Figura 06.

De acordo com a Figura 06, observa-se que o Estado do Rio Grande do Sul, e consequentemente o Parque Estadual de Itapuã estavam no dia 01 de fevereiro de 2013 sob domínio de um Anticiclone Tropical Atlântico e consequentemente sua Massa Tropical Atlântica (MTA), com centro isobárico sobre as latitudes de 30 a $35^{\circ} \mathrm{S}$ sobre o Oceano Atlântico, registrando-se em seu centro pressão atmosférica de $1026 \mathrm{mb}$.

Ainda, no oeste do Rio Grande do Sul dominava na mesma data a Depressão do Chaco, formadora da Massa Tropical Continental (MTC), com centro isobárico sobre o norte da Argentina, registrando pressão atmosférica de $1000 \mathrm{mb}$ (Figura 06).

A Depressão do Chaco, comparando-se os horários de coleta, pode-se observar que entre as $09 \mathrm{~h}$ e às $15 \mathrm{~h}$, registrou-se deslocamento em direção sul, posicionando- 


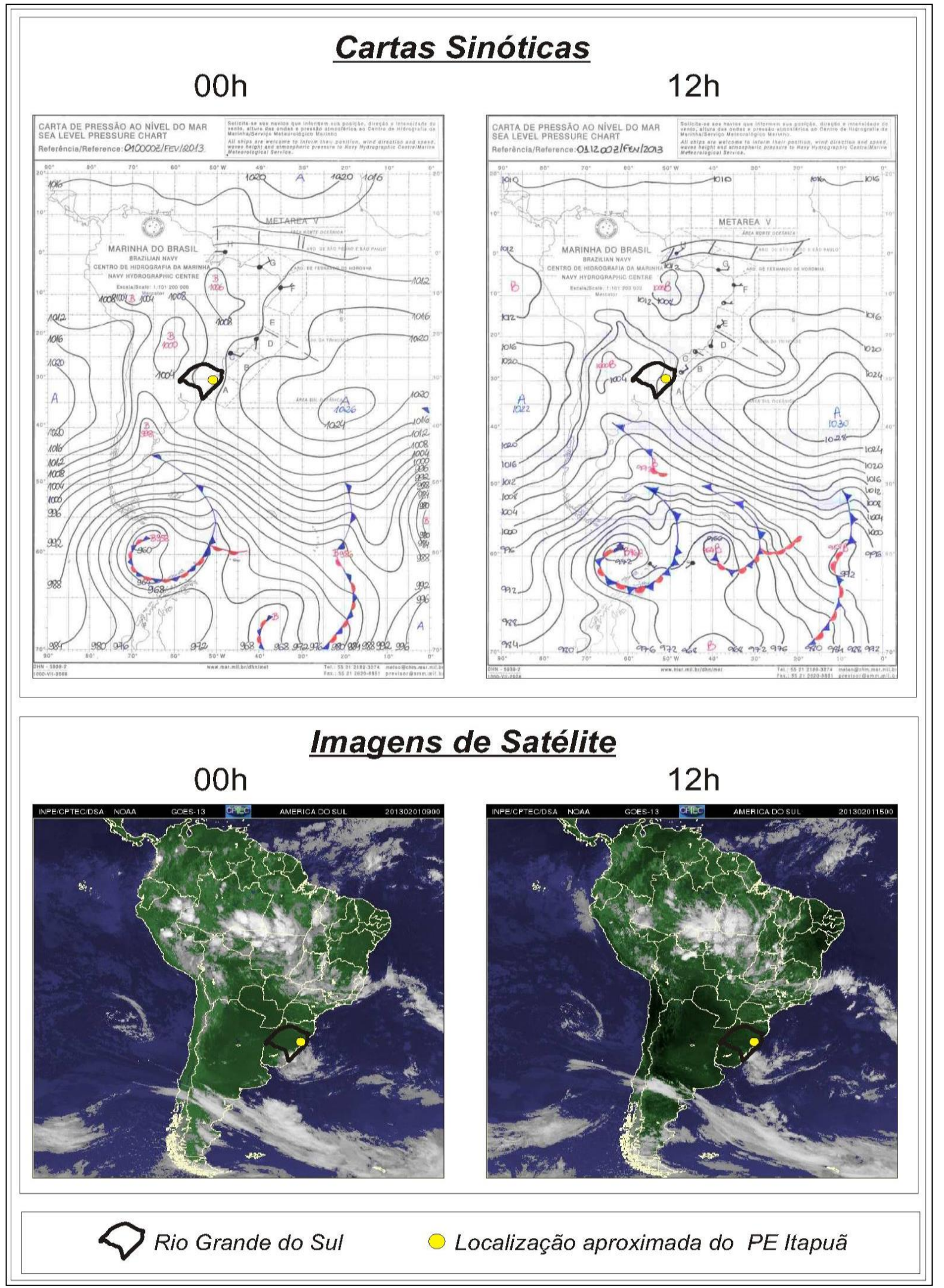

Figura 06 - Cartas Sinóticas e Imagens de Satélite do dia 01/02/2013, com destaque para o Rio Grande do Sul e Parque Estadual de Itapuã.

Fonte: Cartas Sinóticas Marinha do Brasil / Imagens de satélite. CPTEC/INPE

Org.: Wollmann (2013). 
se mais a oeste do Estado, e aumentando seu domínio atmosférico sobre o mesmo.

Nesse sentido, durante a parte da manhã do dia de realização da pesquisa, pode-se aferir que o Rio Grande do Sul, bem como o PEI, estavam sob domínio do Anticiclone Tropical Atlântico e de sua massa derivadora, a Massa Tropical Atlântica. Já na parte da tarde, houve a substituição de domínio atmosférico, passando a dominar sobre o Estado e área de estudo a Depressão do Chaco e sua Massa Tropical Continental.

De acordo com Sartori $(1980 ; 1981 ; 2003)$ e Wollmann; Sartori (2009) pode-se classificar este quadro sinótico como de Domínio Tropical Atlântico seguido por Domínio Tropical Continental (ou Depressionário Continental), com aproximação de nova Frente Polar Atlântica.

De acordo com Sartori (2003, p. 30), esse tipo de sucessão do tempo e de domínios atmosféricos no Estado pode ser entendido como:

Entre os Sistemas Intertropicais, a MTA, incluindo sua interiorização (MTAc), e a MTC são as que têm maior participação na circulação atmosférica regional, dominando em cerca de 5\% dos dias cada uma. Esses sistemas, de permanência efêmera, prevalecem na região somente nas fases pré-frontais em substituição à MPV, devido à fusão entre o Anticiclone Polar Atlântico (APA) e o Anticiclone Tropical Atlântico (ATA), gerando um único centro de alta pressão. Quando da sua atuação, registram-se elevação das temperaturas e declínio da pressão atmosférica e da umidade relativa, mais acentuado no domínio da Tropical Continental.

A posição do centro de ação do Anticiclone Tropical Atlântico dava-se sobre o oceano de mesmo nome, dado à fusão com o Anticiclone Migratório Polar no dia anterior, e que ainda podia ser vista pela representação de processo de frontólise na carta sinótica. Nesse sentido, na manhã do dia da coleta, as condições meteorológicas e sinóticas caracterizavam a participação do tipo de tempo Anticiclônico Tropical Atlântico; enquanto que na parte da tarde, com o domínio da Baixa do Chaco, passou a dominar o tipo de tempo Depressionário Continental.

Segundo Sartori (op. cit., p. 33-34), tais tipos de tempo podem ser caracterizados da seguinte forma, de acordo com suas impressões sinóticas no espaço geográfico:

Tempo Anticiclônico Tropical Marítimo - estado atmosférico semelhante ao do Tempo Anticiclônico Polar em Tropicalização, mas relacionado ao domínio na região da MTA, que origina tempo bom, com fluxos predominantemente de nordeste (NE) e leste (E) leves, temperaturas elevadas (entre $19^{\circ} \mathrm{C}$ e $35^{\circ} \mathrm{C}$ ), céu limpo e formação de orvalho. Em geral, tem duração efêmera, isto é, no máximo dois dias, em virtude de anteceder a chegada da FPA, substituindo a MPV na fase pré-frontal, quando se dá a fusão do Anticiclone Polar com o ATA.
Tempo Depressionário Continental - resulta da expansão da Massa Tropical Continental, devido ao aprofundamento da Depressão do Chaco, que eventualmente atinge o Rio Grande do Sul. Esse tipo de tempo é dos mais característicos, pois as temperaturas máximas são quase sempre superiores a $35^{\circ} \mathrm{C}$, com pressão atmosférica muito baixa (inferiores às demais situações pré-frontais sob domínio da MPV, da MTA ou da MTAc), baixa umidade relativa pela origem continental da massa de ar e pela forte insolação, ventos do quadrante oeste (W e NW) de intensidade variável.

Nesse sentido, os dados coletados em campo e em comparação com os dados mensurados pela Estação Meteorológica de Porto Alegre/RS, pertencente à Rede INMET, com registro de temperatura do bulbo seco entre $28^{\circ} \mathrm{C}$ e $36^{\circ} \mathrm{C}$ (e amplitude de aproximadamente $8^{\circ} \mathrm{C}$ entre as $09 \mathrm{~h}$ e 15h), umidade relativa do ar entre $68 \%$ e $52 \%$, e pressão atmosférica elevada na parte da manhã e em declínio com quando comparada com os dados da mesma tarde, são as características comuns dos tempos levantados em relação à dinâmica atmosférica pertinente no dia 01 de fevereiro de 2013, que se insere em condições normais de hemisfério aquecido pelo verão.

\subsection{Variação espacial da temperatura e umida- de no Parque Estadual de Itapuã/RS}

Consoante à metodologia proposta para esta pesquisa, realizou-se o mapeamento da variabilidade espacial dos atributos do clima com a finalidade de observar se houve relação entre os mesmos e os controles climáticos do Parque Estadual de Itapuã.

Nesse sentido, as Figuras 07 e 08 mostram a variabilidade espacial da temperatura do bulbo seco e úmido para os dois horários de coleta ( 9 h e 15h) do dia 01 de fevereiro de 2013.

De acordo com a Figura 07, que trata da espacialização da temperatura do bulbo seco na área do transecto no Parque Estadual de Itapuã, a TBS apresentou-se às $9 \mathrm{~h}$ com maiores registros no setor norte da área de coleta, que corresponde à Praia das Pombas e Morro da Fortaleza (Pontos 08 e 15), em comparação com o sul da área pesquisada, registrando valores inferiores de até $2,0^{\circ} \mathrm{C}$ (próximo ao Ponto 05 ). A área com maior registro de TBS possui como característica topográfica o fato de possui suas vertentes voltadas para o Leste e Norte, o que explicaria o maior aquecimento em comparação com as áreas de menor registro de TBS, cujas vertentes possuem orientação Sul e Oeste.

No que tange o registro das $15 \mathrm{~h}$, as áreas que tiveram maior aquecimento do ar são justamente aquelas que possuem orientação de vertente para Oeste (Pontos 09 a 14), e as áreas com exposição Leste são as que menos aqueceram em comparação com os registros da manhã (Pontos 01 a 05).

Em ambos os horários, a TBS não apresentou relação com o uso e cobertura do solo, pois, tanto às $9 \mathrm{~h}$ quanto 


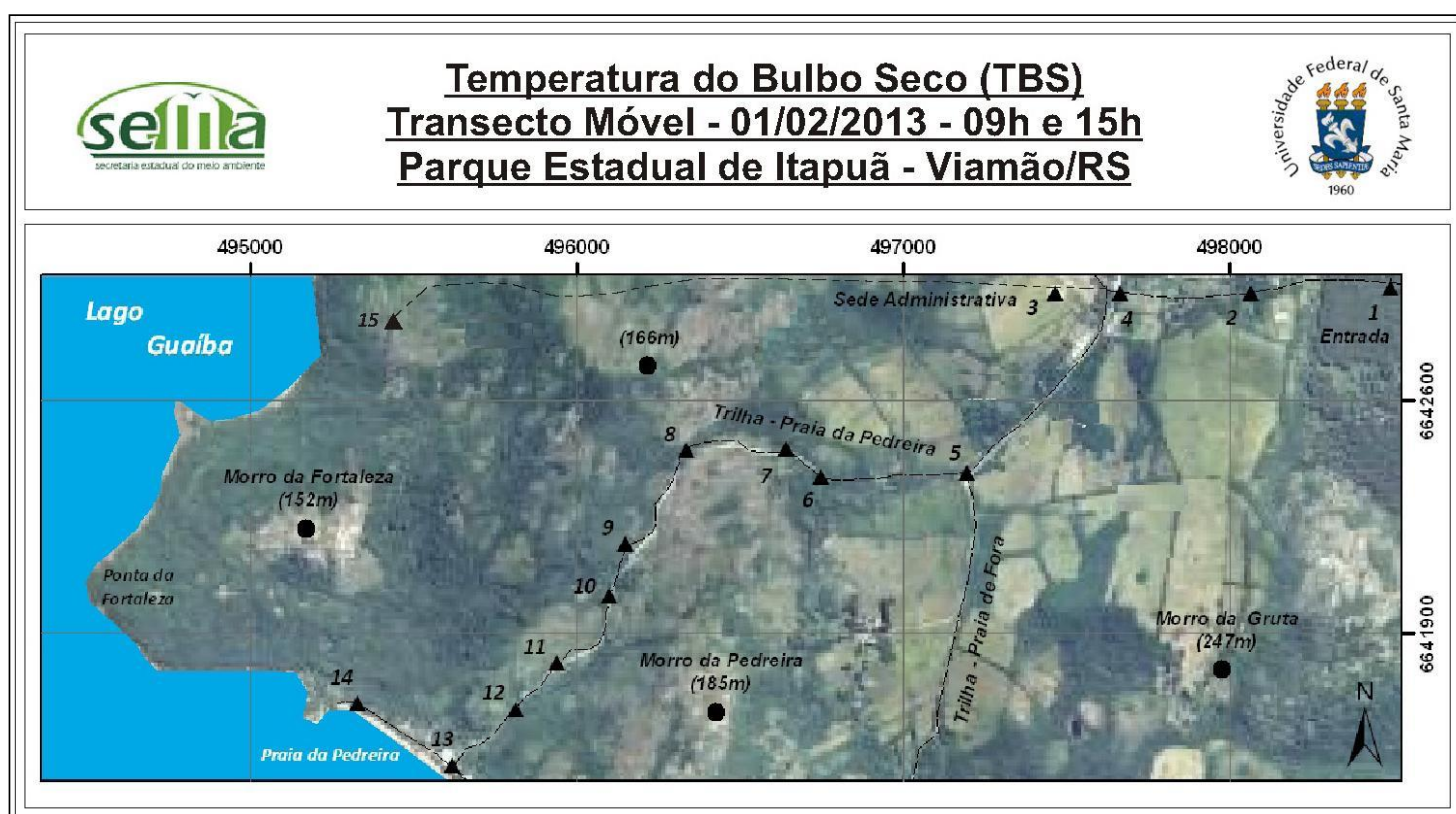

Figura A - Imagem de satélite com uso do solo e cobertura vegetal na área de estudo

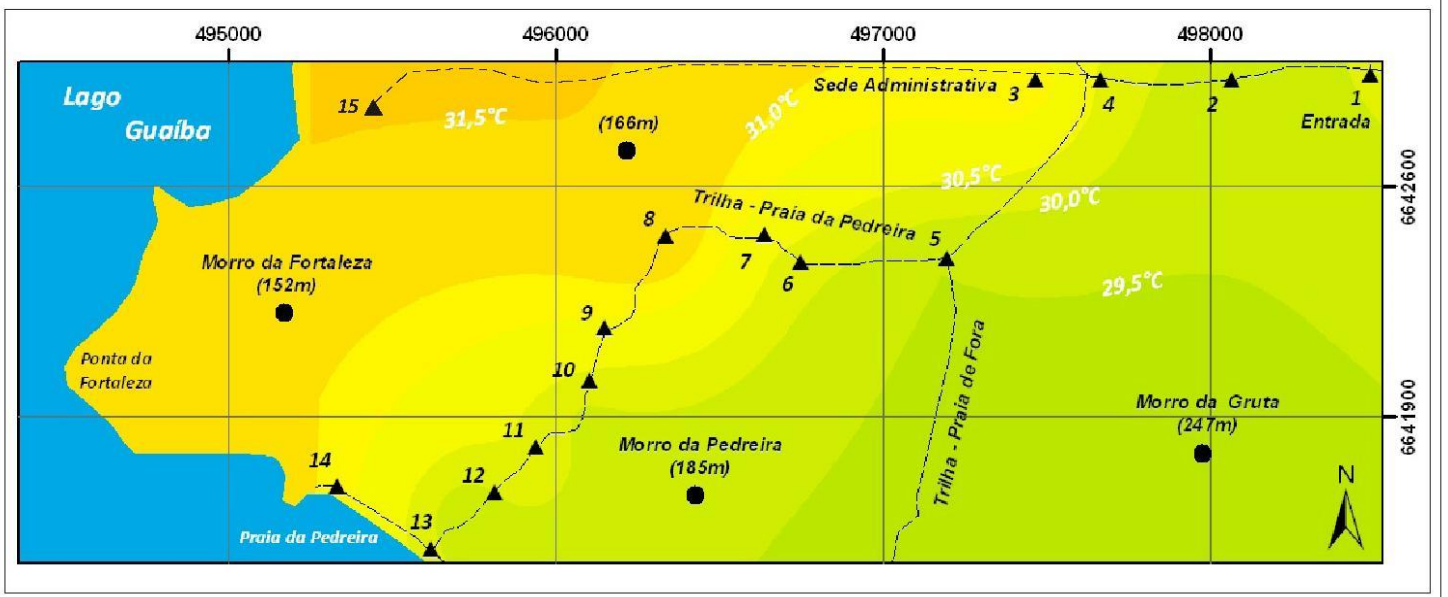

Figura B - Variação espacial da TBS, às 09h, no PEI (Transectos)

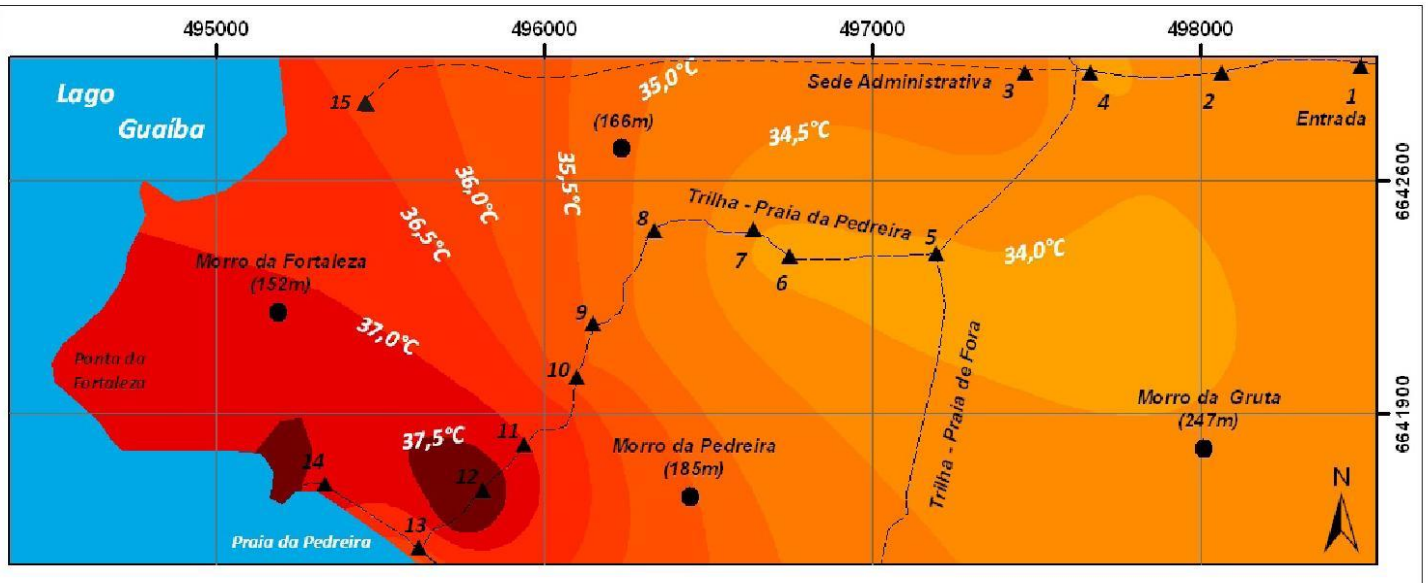

Figura C - Variação espacial da TBS, às 15h, no PEI (Transectos)

Figura 07 - Variabilidade espacial da temperatura de bulbo seco no PEI.

Org.: Wollmann (2013). 


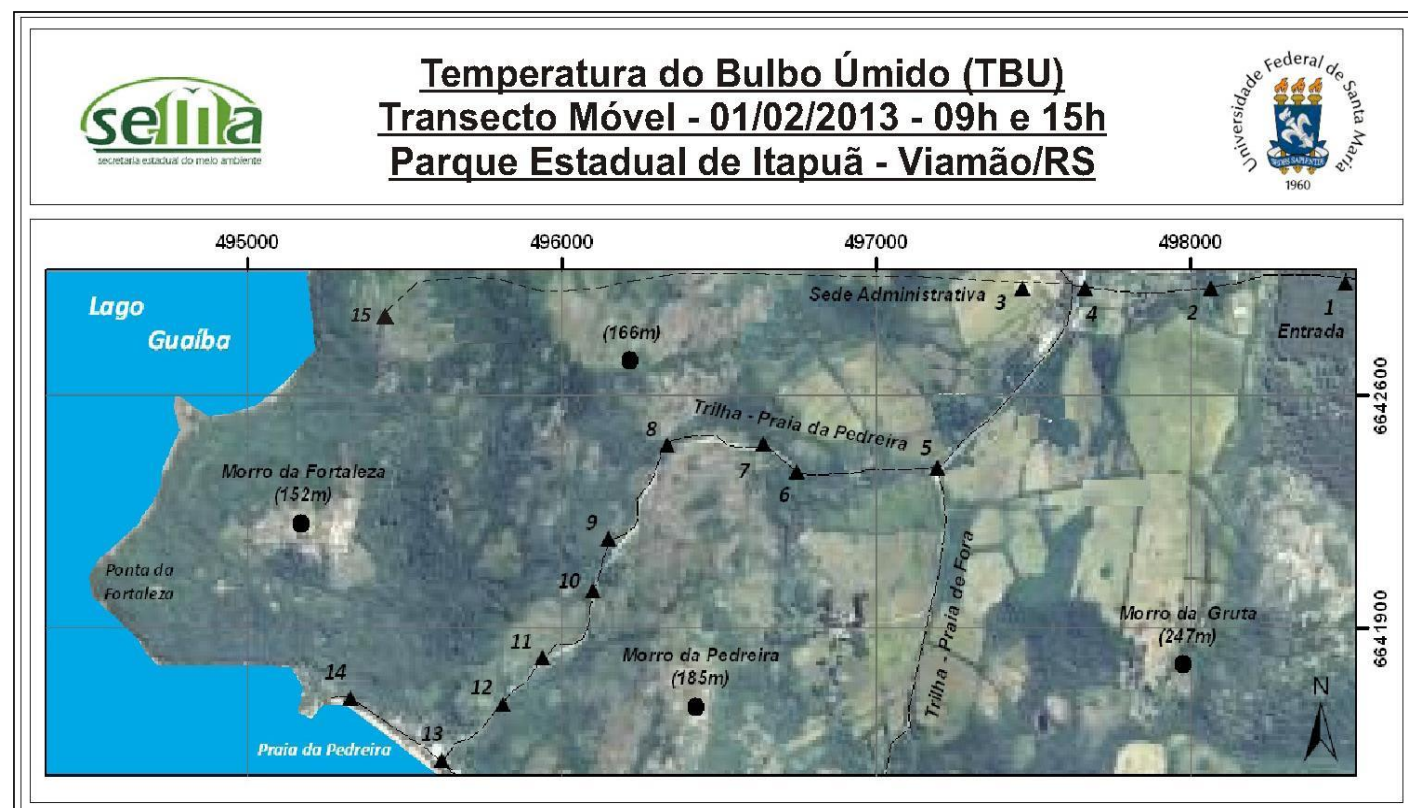

Figura A - Imagem de satélite com uso do solo e cobertura vegetal na área de estudo

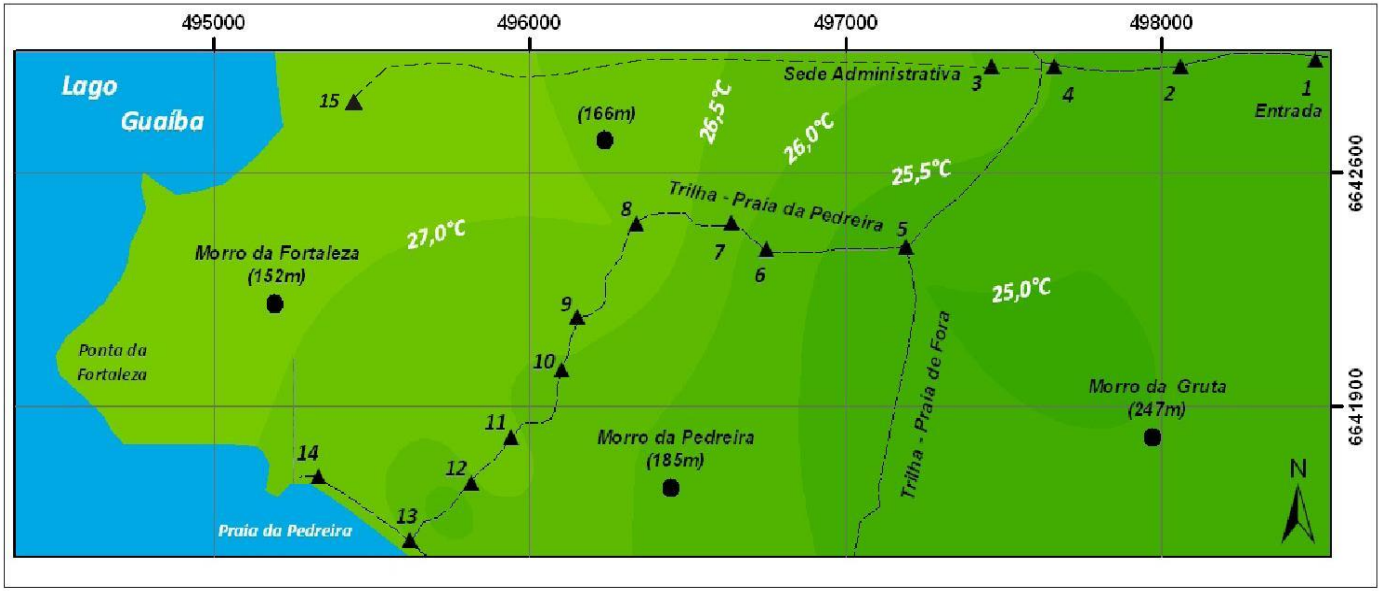

Figura B - Variação espacial da TBU, às 09h, no PEl (Transectos)

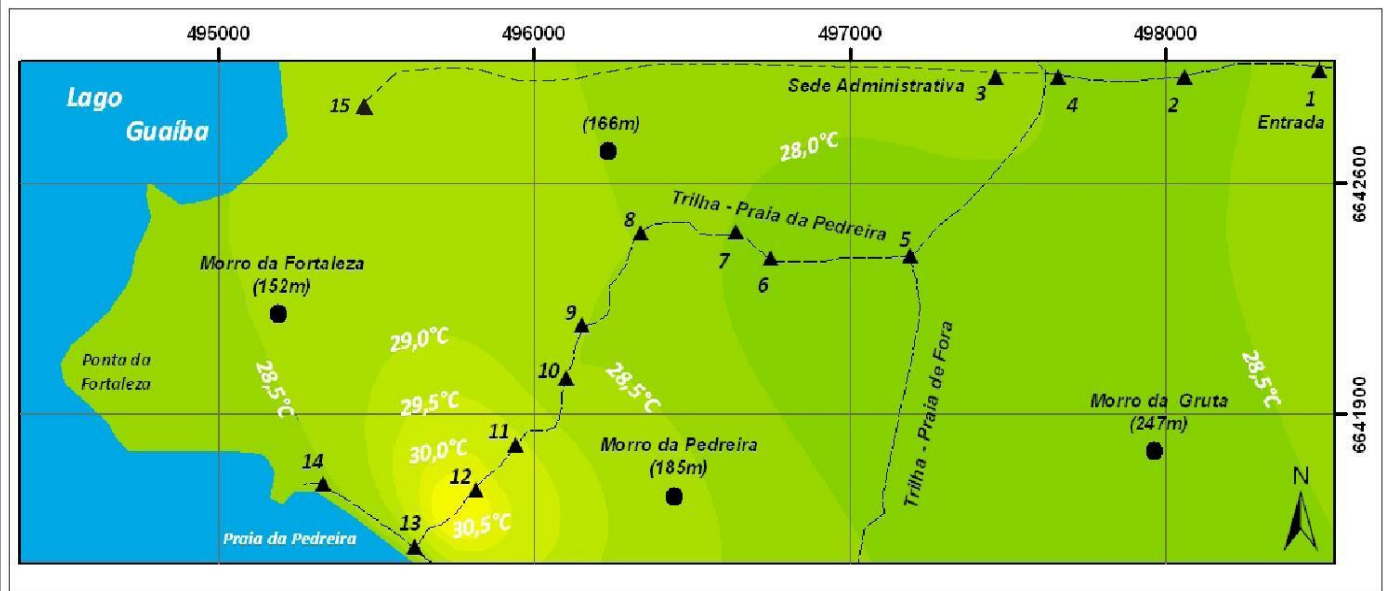

Figura C - Variação espacial da TBU, às 15h, no PEI (Transectos)

Figura 08 - Variabilidade espacial da temperatura de bulbo úmido no PEI.

Org.: Wollmann (2013). 


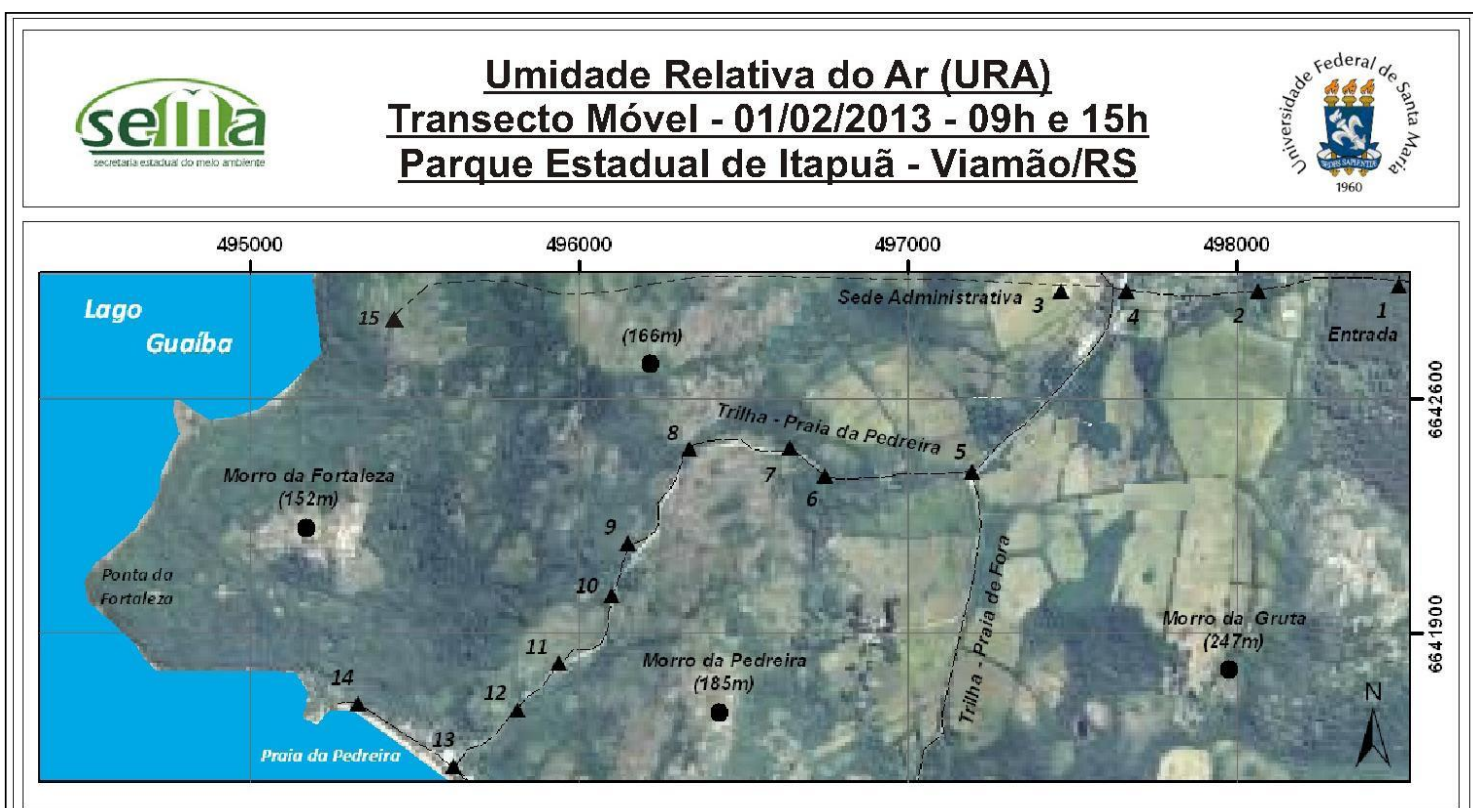

Figura A - Imagem de satélite com uso do solo e cobertura vegetal na área de estudo

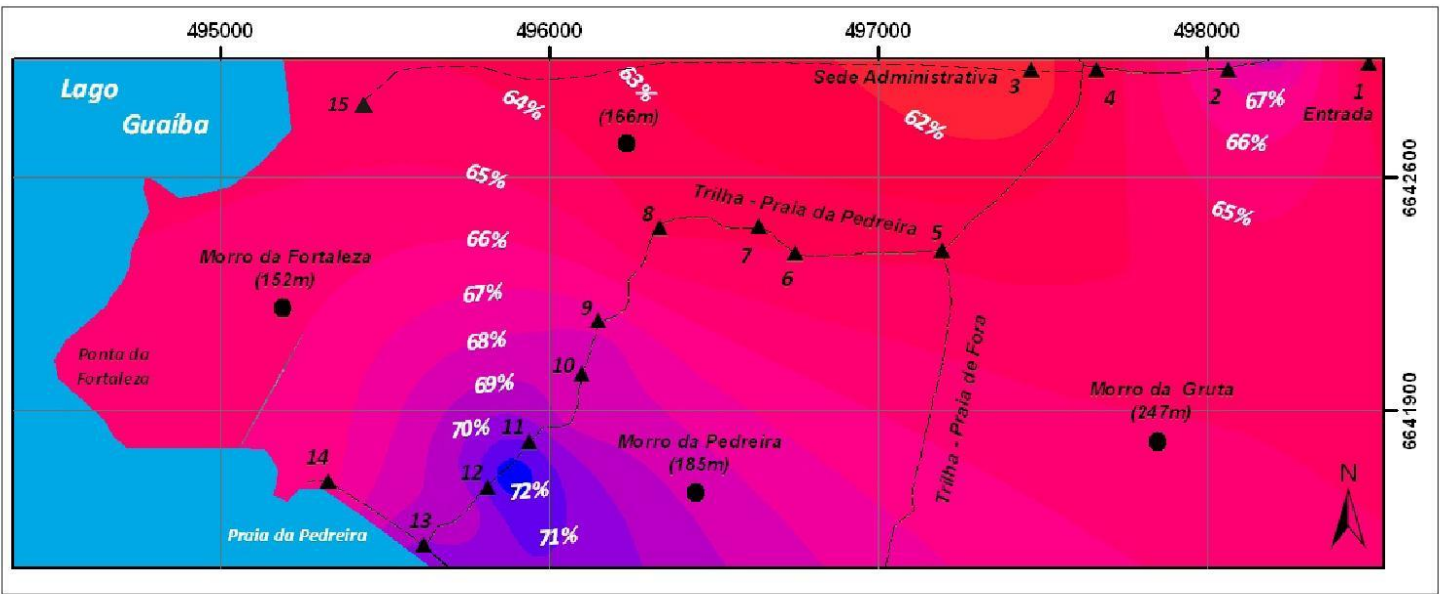

Figura B - Variação espacial da URA, às 09h, no PEI (Transectos)

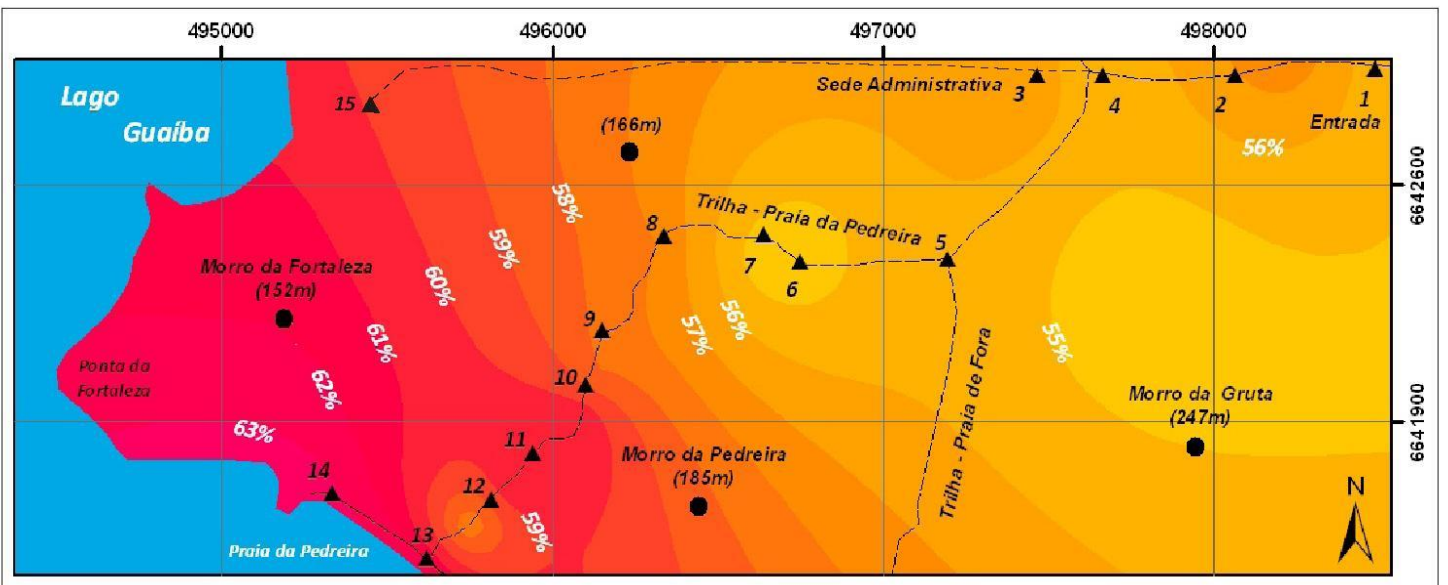

Figura C - Variação espacial da URA, às 15h, no PEI (Transectos)

Figura 09 - Variabilidade espacial da umidade relativa do ar no PEI.

Org.: Wollmann (2013). 
às $15 \mathrm{~h}$, justamente as áreas de maior presença de vegetação, que correspondem aos Morros da Fortaleza e Pedreira, com maior densidade de vegetação, foram as áreas com maior registros em ambos horários e com maior amplitude térmica entre os horários de realização da coleta. Ainda, o contrário pode ser observado nas áreas de campo ou de regeneração (à leste do Ponto 05 e sul do Ponto 02), áreas nas quais os menores registros de TBS estiveram associados à vegetação de baixo porte e/ou rasteira.

Em relação à Figura 08, que trata da espacialização da temperatura do bulbo úmido na referida Unidade de Conservação, a TBU, como era de se esperar, apresentou variabilidade de forma semelhante à TBS em ambos horários de coleta. Sua maior variabilidade espacial deu-se, nos dois horários, especialmente, entre os Pontos 06 e 12, que correspondem às áreas entre os Morros da Fortaleza e Pedreira, podendo-se concluir, ainda que preliminarmente, o efeito da altitude sobre a variação da TBU no Parque Estadual de Itapuã. As áreas próximas às Praias das Pombas e Pedreira, justamente por estarem localizadas próximas aos principais corpos d'água, não apresentaram significativa influência sobre os registros de TBU.

Assim como na TBS, a máxima amplitude térmica da TBU no parque não ultrapassou $2,0^{\circ} \mathrm{C}$ entre os dois horários de coleta. Nesse sentido, salienta-se que sob tais condições atmosféricas, a amplitude térmica no PEI não seja elevada, contrariamente ao que ocorre com a URA (Figura 09).

A Figura 09, por sua vez, apresenta a espacialização da umidade relativa do ar no Parque Estadual de Itapuã, que, ao analisarmos as diferenças higrométricas entre a coleta das $9 \mathrm{~h}$ e das $15 \mathrm{~h}$, pode-se observar considerável amplitude entre esses registros. Comparando-se visualmente a Figura 07 e a Figura 09, observa-se que ambos os atributos climáticos possuem grande consonância com a orientação de vertentes, e especialmente por que a URA depende inversamente proporcional aos valores de TBS.

A URA também registrou menores valores às $9 \mathrm{~h}$ da manhã nos locais que a TBS foi maior, ou seja, justamente nos Pontos 01 a 08 e 15 (setor norte da área estudada), bem como os menores valores foram registrados nas áreas de maior valor da TBS (Pontos 09 a 13).

Em relação aos registros da URA às 15h, observa-se um quadro climático diferente: as áreas com maior registro de URA são justamente aquelas nas quais também houve maior registro de TBS, mas que equivalem às áreas de maior altitude e de maior cobertura vegetal de grande porte (Pontos 05 a 15), enquanto que as áreas de menor registro de URA equivalem àquelas com predomínio de campos de vegetação de menor porte. Entretanto, a amplitude higrométrica foi quase a mesma quando comparada com os valores registrados na parte da manhã: $8 \%$ e $9 \%$, respectivamente.

\section{Consideração finais}

Com a realização inicial desta pesquisa, espera-se em primeiro lugar, poder humildemente iniciar a contribuição científica do clima para o estudo das Unidades de Conservação (UC) brasileiras, especialmente as localizadas no Estado do Rio Grande do Sul, como o Parque Estadual de Itapuã, de grande importância para a biota. Ainda, no âmago das Unidades de Conservação, o monitoramento climático das mesmas ainda constituise em ramo científico pouco estudado no Brasil, o que pode auxiliar significativamente nos seus Planos de Manejo, não só na sua construção, bem como na sua plena execução de monitoramento.

Independentemente das Unidades de Conservação as regiões lacustres do estado do Rio Grande do Sul carecem de estudos mais aprofundados do ponto de vista da Climatologia Geográfica, ciência tão em voga nos últimos anos em função de discussões acerca de novos padrões climáticos. Nesse sentido, essa região lacustre, especialmente sua porção central, que compõe os relevos de transição entre os escudos cristalinos e os sedimentos quaternários, com vegetações de restingas oceânicas associadas ao Pampa a à Mata Atlântica, esta pesquisa procurou contribuir para o entendimento da dinâmica climática nessas áreas, ainda carentes de proteção legal.

O Parque Estadual de Itapuã, do ponto de vista do clima, que pode parecer "homogêneo" em uma análise superficial, mas que após análise in loco, mostrou-se tão diverso e dinâmico quanto à natureza viva do local, especialmente nas variações térmicas e higrométricas, associadas aos principais controles climáticos locais: vegetação, altitude e corpos hídricos.

Nesse sentido, conclui-se que a temperatura do bulbo seco teve sua variabilidade entre os dois horários associada exclusivamente à orientação das vertentes, enquanto que a temperatura do bulbo seco à altitude nos diversos pontos de coleta. Já a variação da umidade relativa do ar esteve ligada, na parte da manhã, à orientação das vertentes, e na parte da tarde, à presença de vegetação de maior porte.

Cabe salientar ainda que os elevados registros de temperatura deram-se em função dos sistemas atmosféricos de origem tropical que dominavam no dia da coleta, mas que não registraram significativa diferença quando comparado com os valores oficiais da Estação Meteorológica de Porto Alegre, da Rede INMET.

Ainda, contrariando algumas hipóteses, a presença de grandes corpos hídricos (Lago Guaíba e Laguna dos Patos) não se destacaram como importantes controles à variabilidade climática no Parque Estadual de Itapuã. Entretanto, não se pode concluir que tais corpos hídricos não possuem interferência, uma vez que se trata de um estudo preliminar realizado durante um dia com quadro sinótico definido como tropical. Nesse sentido, motivam-se investigações futuras em relação à variabilidade dos atributos do clima e sua relação com os 
controles geográficos em outras situações atmosféricas.

Ainda, o estudo do clima nesta unidade de conservação motiva o autor a continuar projetos em andamento na área, e que futuramente, poderão evidenciar se estes padrões espaciais de variação dos atributos do clima se repetem em escalas de análise mensal, sazonal e anual.

\section{Referências}

\section{FUNDAÇÃO ZOOBOTÂNICA DO RIO} GRANDE DO SUL (FZBRS). Mapa das Ecorregiões do Rio Grande do Sul. Disponível em: <http://www.biodiversidade.rs.gov.br/ arquivos/1162476674ecorreg_rs.jpg> Acesso em: 05 de outubro de 2013.

\section{GERM. 1975. Ver RIO GRANDE DO SUL Grupo} Executivo da região Metropolitana.

KOURY, C. G.; RIZZO, E.; FREITAS, C.; et. al. Inclusão de Discussões de Mudanças Climáticas na Gestão de Unidades de Conservação. Manaus: Instituto de Conservação e Desenvolvimento Sustentável do Amazonas, 2011.

LIMA, N. G. B. Análise Microclimática dos Manguezais da Barra do Ribeira-Iguape/SP. Dissertação de Mestrado (Mestrado em Geografia Física). Universidade de São Paulo. São Paulo, 2009. 203p.

\section{MINISTÉRIO DO MEIO AMBIENTE (MMA). Mapa} Ilustrativo do Sistema Nacional de Unidades de Conservação da Natureza. 2011.

Disponível em: $<$ http://www.ambientebrasil.com. br/images/mapas/uc_todas.pdf $>$ Acesso em: 08 de outubro de 2012.

PLANO DE MANEJO - Parque Estadual de Itapuã. Porto Alegre: Secretaria da Agricultura e Abastecimento / Departamento de Recursos Naturais Renováveis. 1996.

RIO GRANDE DO SUL. Grupo Executivo da Região Metropolitana (GERM). 1975.

Plano piloto - Parque Regional de Itapuã. Porto Alegre. 2v.

SARTORI, M. G. B. A dinâmica do clima do Rio Grande do Sul: indução empírica e conhecimento científico. Revista Terra Livre. São Paulo Ano 19 vol. I - n. 20 p. 27-49 jan/jul. 2003.
SEMC - SECRETARIA ESTADUAL DE MINAS, ENERGIA E COMUNICAÇÕES. Governo do Estado do Rio Grande do Sul. Atlas Eólico do Rio Grande do Sul. Porto Alegre, 2002. 65p.

SERAFINI JR., S. O Microclima de uma Vereda Degradada: Estudo de Caso no Parque Estadual Veredas do Peruaçu - MG. Tese (Doutorado em Geografia Física). Universidade de São Paulo. São Paulo, 2010. 140p.

VOLKMER-RIBEIRO, C. Limnologia e a vegetação de macrófitas na Lagoa Negra, Parque Estadual de Itapuã, Rio Grande do Sul. Iheringia. Sér. Bot., Porto Alegre, (27): 41-68. 1981.

WOLLMANN, C. A.; SIMIONI, J. P. D. Variabilidade Espacial dos Atributos Climáticos na Estação Ecológica do Taim (RS), sob Domínio Polar. Revista do Departamento de Geografia (USP), v. 25, p. 7898, 2013. 